\title{
The treatment of osteoarthritis
}

\author{
ADRIAN C. JONES \& MICHAEL DOHERTY \\ Rheumatology Unit, City Hospital, Nottingham NG5 1PB
}

1 The treatment of osteoarthritis is currently purely symptomatic. To enable rational therapy, careful clinical assessment is necessary to identify the origin of symptoms. Often, effective therapy can result from a biomechanical approach such as surgery, orthotics, physiotherapy and dieting. If drugs are required, there is little evidence that the current over-reliance on non-steroidal anti-inflammatory drugs (NSAIDs) is justified. Full dose regular paracetamol should be the first line of analgesic therapy. In the majority of patients, simple analgesics are probably as effective as NSAIDs. If NSAIDs are used it is necessary to review regularly their use and to be aware of potential toxicity.

2 Many alternative strategies of pain management such as topical preparations, intraarticular steroid injections, acupuncture, radiosynovectomy, transcutaneous nerve stimulation and anti-depressants, may be effective but their precise place in the armamentarium is not yet fully established.

3 The realisation that osteoarthritis is not a passive 'wear and tear' phenomenon but an active process that may be potentially modified, has led to interest in 'chondroprotective' agents, which may beneficially affect the osteoarthritic process. To date there are no convincing data available that such agents are, in fact, chondroprotective in humans.

Keywords osteoarthritis treatment chondroprotection analgesics non-steroidal antiinflammatory drugs

\section{Introduction}

Osteoarthritis (OA) is the commonest affliction of synovial joints (Office of Population Censuses and Surveys, 1983) with structural (radiological) joint changes of OA, (Figure 1), present in approximately half of the adult population (Felson et al., 1990; Lawrence et al., 1966). However symptoms are present in a smaller proportion depending on the joint involved (Bagge et al., 1991; Felson et al., 1990; Lawrence et al., 1966). Structural OA may thus be regarded as either symptomatic or asymptomatic and optimal treatment requires identification as to which of many possible mechanisms are responsible for producing symptoms (Figure 2).

The realisation that $\mathrm{OA}$ is not simply a passive "wear and tear' phenomenon but an active process, that has been phylogenetically preserved (Hutton, 1987), and which can be associated with good functional outcome (Mejersjo, 1987; Pattrick et al., 1989), has produced the concept of OA as a 'process' rather than a 'disease', representing the normal reparative response to joint insult (Radin \& Burr, 1984). Consequently there exists the possibility of manipulating this process towards a favourable outcome. This underlies recent interest in 'chondroprotective' agents (CPAs), which may maintain cartilage and thus possibly, joint function.

Assessment of response to treatment involves three components. Firstly the patient's desire is for symptom relief and thus his/her self-assessment of response is paramount. Secondly there is a need to maintain or improve function: a variety of 'instruments', (predominantly questionnaires), are now available to assess this aspect. Thirdly, if the OA process can be modified, then a sensitive, objective measure of response is required. Currently this involves long-term estimation of gross structural change, but ultimately more sensitive measures of structural change (e.g. microfocal radiography (Buckland-Wright et al., 1990)) or biochemical markers of physiological change (e.g. keratan sulphate (Thonar et al., 1985)) may prove relevant.

\section{Mechanisms of symptoms in OA}

The source of symptoms in OA is often unclear and may be multifactorial (Figure 2) (Kantor, 1989; Merritt, 


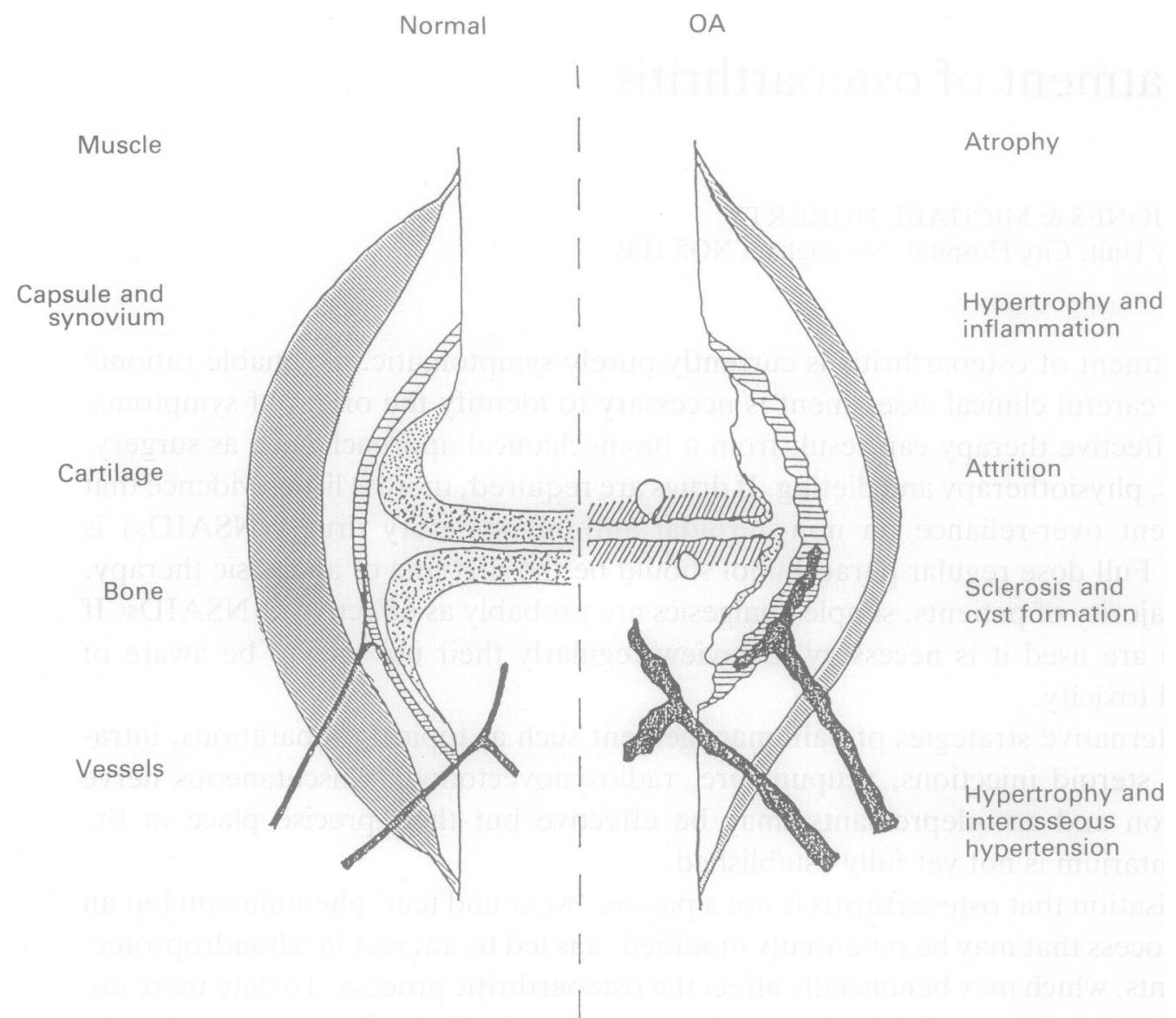

Figure 1 The morphological changes that occur in the osteoarthritic joint.

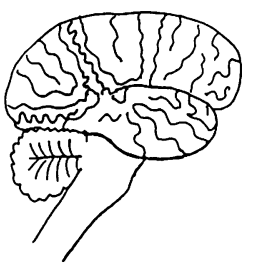

Higher centres

Depression

Fibromyalgia

Anxiety

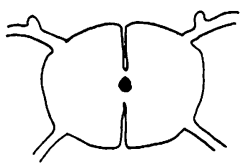

Spinal cord

Gating

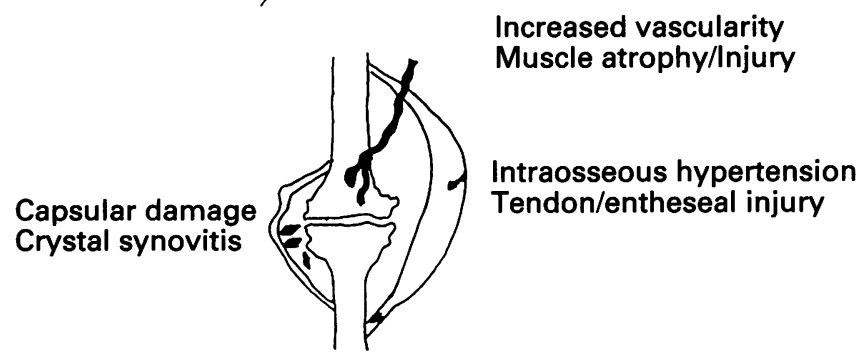

Figure 2 Possible sources of symptoms in osteoarthritis.

1989). Elucidating those that are important in an individual patient should enable targetted therapy. The usual symptom for which the patient seeks relief is pain. Cartilage is avascular and aneural and it is unlikely that symptoms arise directly from its destruction. However there are associated changes in other joint tissues which may be symptomatic. Alterations in cartilage matrix may promote crystal formation and shedding, resulting in episodes of inflammation. Pain may be further modulated by the brain and spinal cord (Kantor, 1989; Merritt, 1989).

Other symptoms, e.g. stiffness or loss of function, must also be addressed but their underlying mechanisms are poorly understood. They may however include capsular fibrosis, tendon contracture, muscle atrophy, muscle inhibition and reduced fitness.

Assessment of the OA patient is primarily clinical. Although it has been suggested that the nature of the pain may be of help, i.e. nocturnal pain representing intraosseous hypertension, in practice this is rarely of assistance. Duration is an important consideration since recent deterioration merits consideration of superimposed pathology, e.g. sepsis or avascular necrosis. A marked inflammatory component is suggested by symptoms of prolonged early morning and inactivity stiffness, and signs of warmth, effusion and 'stress' pain. The examination is also directed to determining the precise site of maximal tenderness, eg joint line (probably synovitis) or periarticular. Multiple periarticular and muscular tender sites should prompt consideration of the fibromyalgia syndrome (Goldenberg, 1987) particularly if associated with sleep disturbance. Finally consideration should be made of the patients affect since this may be as important as structural damage in influencing the degree of disability and pain experienced by the patient. 


\section{Biomechanics}

Symptoms arising from adverse biomechanical factors, (e.g. obesity, malalignment, instability) are best treated biomechanically, utilising the expertise of the dietician, physiotherapist, occupational therapist, orthotist and surgeon. It is important to identify such factors since appropriate therapy is often effective and probably less hazardous than inappropriate medication.

\section{Analgesia}

The optimal management of pain in OA requires identification of its source (Figure 2). For example, much pain in OA appears to be periarticular and appropriate local measures, e.g. periarticular steroid injections, may be effective. If analgesia is required, paracetamol should be used at maximum dosage before progressing to nonsteroidal anti-inflammatory drugs (NSAIDs). Nefopam, codeine phosphate, dihydrocodeine or combination preparations (e.g. coproxamol) are often used though any increase in efficacy may be offset by greater toxicity (Kjaersgaard-Andersen et al., 1990; Parr et al., 1985; Stamp et al., 1989). Indeed evidence for improved efficacy in OA over paracetamol is scanty (Brooks et al., 1982; Kjaersgaard-Andersen et al., 1990). Stronger opioids should not be used; uncontrolled pain requires re-evaluation or an alternative approach such as a regional nerve block (Pybus, 1987) or surgery.

Local heat, such as provided by rubifacients, may be beneficial. Similarly acupuncture, and transcutaneous nerve stimulation (Lewis \& Lewis, 1985) may be beneficial, though convincing evidence for either is sparse. All may act by modulating pain 'gating' (Wall, 1984) (Figure 2).

Depression is often a feature of chronic pain (Gershon, 1986) and in addition many anti-depressants have analgesic properties (Gershon, 1986). Surprisingly little is known of the incidence of depression and anxiety in OA (Summers et al., 1988) nor of the efficacy of antidepressants.

\section{Non-steroidal anti inflammatory drugs}

NSAIDs are widely used, but although inflammation may be a feature of OA (Altman \& Gray, 1985; Huskisson et al., 1979), there is little evidence that NSAIDs are acting other than as analgesics. Their superiority over simple analgesics is poorly documented (Doyle et al., 1981; Parr et al., 1985). A recent large, double-blind, placebo-controlled study of paracetamol ( $4 \mathrm{~g}$ daily) vs ibuprofen at either analgesic (1.2 $\mathrm{g}$ daily) or antiinflammatory ( $2.4 \mathrm{~g}$ daily) doses, failed to demonstrate any increased benefit from the NSAID (Bradley et al., 1991).

However NSAIDs are responsible for $25 \%$ of all 'yellow card' reports (Committee for the Safety of Medicines, 1986). Whilst individuals are at low risk, the total associated morbidity and mortality from NSAIDs is high (Bloom 1988; Somerville et al., 1986). Furthermore NSAIDs may not always be used appropriately (Jones et al., 1992; Steele et al., 1987); careful, regular re-evaluation of use is required by both prescriber and patient.

For the minority in whom NSAIDs cannot be substituted by simple analgesics (Bradley et al., 1991; Dieppe et al., 1990; Jones et al., 1992) it would seem wise, particularly in elderly females who may be at increased risk (Blackshear et al., 1985; Somerville et al., 1986), to monitor for adverse effects (Blackshear et al., 1985; Paulus, 1985). Although such monitoring has been widely recommended both by manufacturers and others (Blackshear et al., 1985; Paulus, 1985), the optimum method has not been specified.

Ideally, since acute deterioration in renal and hepatic function may occur in patients recently commenced on NSAIDs (Blackshear et al., 1985), renal and liver function should be measured prior to, and 2-4 weeks after, starting the drug. Iron deficiency anaemia may result without evidence of overt gastrointestinal bleeding and six monthly full blood count might be appropriate.

Differences in the safety profiles of different NSAIDs have yet to be established (Carson et al., 1987; Caruso \& Biandu Porro, 1980; Coles et al., 1983; Committee for the Safety of Medicines, 1986; Griffin et al., 1991; Paulus, 1985). There are many methodological difficulties including: the difficulty of establishing equipotent doses; self-selection of patients in non-randomised surveys; and bias in retrospective surveys. Since NSAIDs are given for symptom relief only, the smallest dose that provides this should be used.

Alternative methods of administering NSAIDs have been developed in an attempt to reduce side effects, particularly gastropathy. However adverse effects on the stomach result primarily from systemic absorption, and a reduction in clinically important adverse effects from rectal administration, pro-drugs, enteric-coating or the use of prophylaxis is uncertain (Caruso et al., 1985). Transcutaneous administration may however produce equivalent symptomatic relief to oral preparations (Doogan, 1989; Golden, 1978; Shamzad et al., 1986) but whether they are more effective than simple rubifacients is unclear.

\section{Other approaches to inflammation}

Intra-articular steroid injections are simple to administer and safe; the incidence of the main feared side-effect, sepsis, is estimated at only 1:14000-50000 injections (Gray et al., 1981). Intra-articular steroids undoubtedly provide symptomatic relief, but this is transient and there is a significant 'placebo' response (Dieppe et al., 1980; Friedman \& Moore, 1980). Longer acting preparations (e.g. triamcinolone hexacetonide) are more effective (Valtonen, 1981) and it may be that different joints show different responses to steroids (Flanagan $e t$ al., 1988; Mayer, 1970). In spite of fears to the contrary, repeated injections do not appear harmful (Keagy \& Keim, 1967). Indeed animal work suggests that corticosteroids may even be chondroprotective (Pelletier \& Martel-Pelletier, 1989). However the role of intraarticular steroids in OA remains controversial (Gray et al., 1981; MacAlindon \& Dieppe, 1990).

Hypoxic reperfusion injury may be a mechanism whereby damage occurs in inflammed joints (Blake et al., 1989). Intra-articular orgotein, a bovine super-oxide 
dismutase, could theoretically limit this damage. A placebo-controlled, double-blind study of 139 inflammatory OA knee patients demonstrated that those who received orgotein were less likely to withdraw during the study and had statistically significant improvement in all parameters (McIlwain et al., 1989). A less immediate but more sustained symptomatic relief has been demonstrated with orgotein compared with intraarticular injections of either methyl-prednisolone (Gammer \& Broback, 1984) or betamethasone (Mazieres et al., 1991). These early results do suggest that orgotein is superior to both saline and steroid injections though whether this will prove to be an acceptable form of treatment for significant numbers of patients, in particular for those without inflammatory symptoms, remains to be demonstrated.

Radio-synovectomy with external-beam therapy (Gibson et al., 1973) or intra-articular yttrium (Doherty \& Dieppe, 1981) may be beneficial, but its role is unclear. The published length of follow-up is too short to eliminate potential long-term adverse effects on the OA process.

\section{Chondroprotective agent}

It has long been suggested that NSAIDs may hasten joint destruction (Coke, 1967). However since first described the existence of 'Indocid' or 'analgesic' hip as a specific entity has been doubted (Coke, 1967): identical, rapidly progressive changes can certainly be observed in patients not taking NSAIDs (Doherty et al., 1986). Although two studies have demonstrated increased NSAID usage in patients with accelerated hip destruction (Newman \& Ling, 1985; Ronningen \& Langeland, 1979) their retrospective nature makes accurate interpretation difficult. A 2-year prospective, placebo-controlled study of 89 patients with knee OA failed to demonstrate increased progression in those taking diclofenac (Dieppe et al., 1990).

In an attempt to determine if there are clinically important differences between NSAIDs, the rate of loss of cartilage and time to operation of patients maintained on either indomethacin or azapropazone was assessed prospectively (Rashad et al., 1989). Although a better outcome in terms of longer time to hip replacement and decreased rate of joint space loss was demonstrated in the azapropazone group, this study is readily criticised, for example, in terms of the method of radiographic assessment, lack of blinding, and imprecise criteria for deciding the time of surgery. Indeed patients on indomethacin had less pain, possibly a more important outcome measure, particularly as all patients ultimately underwent surgery (Mann \& Young, 1989). To date there is no good evidence that one NSAID is preferable as regards $\mathrm{OA}$ progression.

However, this interest in possible actions of drugs on the OA process has encouraged investigation of the effects of drugs on joint metabolism although there may currently be an overemphasis on cartilage. It should be remembered that agents such as NSAIDs, may also affect other tissues, such as bone. For example, it is well demonstrated that NSAIDs at standard pharmacological doses may inhibit the formation of heterotopic new bone following hip replacement surgery (Ritter \& Gioe, 1982).
Extrapolations to the clinical situation are difficult if only single tissues are considered.

Notwithstanding this, much in vitro experimental work suggests that NSAIDs and other agents may affect parameters thought to represent the OA process, such as enzymatic activity, cytokine production and cartilage biochemistry (Burkhardt \& Ghosh, 1987). The relevance of this to human OA, however, is questionnable (Doherty, 1989).

Animal models of OA may be of more value and a number have been used (Burkhardt \& Ghosh, 1987; Troyer, 1982). For example various agents which may ameliorate or aggravate the OA process have been used in the Pond-Nuki dog model of OA which involves the response to anterior cruciate ligament section (Pond \& Nuki, 1973). These include potential CPAs such as tiaprofenic acid (TA), glycosaminoglycans polysulphate (GAG-PS), glycosaminoglycan-peptide complex (GPC) and hyaluronic acid. Corticosteroid is also chondroprotective in this model (Pelletier \& Martel-Pelletier, 1989), whereas indomethacin and salicylates are deleterious. Although animal models of OA may not be relevant to human OA (Troyer, 1982) they all tend to give broadly similar results for various putative CPAs (Burkhardt \& Ghosh, 1987).

\section{Human studies of chondroprotection}

Ultimately only long-term studies in humans can demonstrate whether CPAs are beneficial. The many difficulties encountered with such trials relate to problems of long-term compliance, assessment and definition (Altman, 1990). Human OA presents when symptomatic and is diagnosed as OA only when structural change is evident. In animal models the time of onset of the OA process is pre-determined and early or prophylactic treatment can be employed. Meniscectomy results in premature $\mathrm{OA}$ in predisposed individuals (Doherty et al., 1982) and this may be one suitable human model in which to assess CPAs. Alternatively patients with OA at one site may, in the relative shortterm, develop OA in other sites (Massardo et al., 1989) and this rate of acquisition of new sites might be a useful marker of chondroprotection (Dieppe, 1990). In spite of all the difficulties a number of attempts to study CPAs have been made.

\section{Glycosaminoglycans polysulphate}

This is an artificially polysulphated extract of bovine trachea and lung which can be given intra-muscularly, intra-articularly or peri-articularly. Its mechanism of action is largely unknown though laboratory data suggest it stimulates synthesis of a large number of cartilage matrix molecules as well as inhibiting a broad spectrum of degradative enzymes. There is evidence in humans that GAG-PS is readily absorbed into synovial fluid following intra-muscular injection and indeed may be concentrated by damaged or inflamed cartilage to which it may bind (for review see Burkhardt \& Ghosh, 1987).

The clinical use of this agent has been reviewed 
(Rejholec, 1987) but although there are many open studies of its use, blinded controlled studies are less frequent. Several placebo-controlled, double-blind studies have demonstrated symptomatic benefit from GAG-PS in OA (Anderson, 1982; Kerzberg et al., 1987; Pastinen et al., 1988; Siegmeth \& Radi, 1983) although there has been an exception (Chamchan et al., 1989). The basis of any improvements seen in these short-term studies, the longest was one year, is unclear; none provide evidence of chondroprotection.

However one long-term (5 year), single-blind placebocontrolled study has suggested both symptomatic improvement and more importantly a slowing of joint destruction (chondroprotection) in patients treated with GAG-PS (Rejholec, 1987).

\section{Glycosaminoglycan-peptide complex}

GP-C is a complex derived from bovine cartilage and bone marrow which has potential chondroprotective activity (Burkhardt \& Ghosh, 1987). Its use in humans, as an intra-muscular injection has been reviewed (Rejholec, 1987). Again its method of action is largely unknown, though like GAG-PS it appears to inhibit both catabolic enzyme degradation and promote cartilage matrix synthesis (see Burkhardt \& Ghosh, 1987). Its complex nature has made isolation of its active components difficult.

As with GAG-PS, although the agent is available in Europe controlled trials of its efficacy are limited. A 2 year single-blind study of intra-muscular GP-C in hip and knee OA demonstrated a symptomatic response to GP-C but no evidence of chondroprotection was provided (Gramajo et al., 1989).

A long-term (13 year) study of GP-C in patients with hip OA has demonstrated both symptomatic benefit and a slowing of radiographic progression (Rejholec, 1987). Similar results were obtained in a 5-year, placebocontrolled single-blind study of knee and hip OA patients for both GAG-PS and GP-C (Rejholec, 1987). These studies by Rejholec and co-workers do suggest that both GAG-PS and GP-C have condroprotective potential in humans. However, the results need to be replicated in other centres and reservations concerning the blinding techniques and radiographic assessments addressed before the drugs can be confirmed as CPAs.

\section{Tiaprofenic acid (TA)}

Although much in vitro and animal work suggests TA is chondroprotective, human data is lacking. Two small studies demonstrate theoretically beneficial effects of TA on proteoglycans (Reginister et al., 1985) and stromelysin (Vignon et al., 1990), but the clinical relevance of these observations is unclear.

\section{References}

Altman, R. D. \& Gray, R. (1985). Inflammation in osteoarthritis. Clin. Rheum. Dis., 11, 353-365.

Altman, R. D. (1990). Design and conduct of clinical trials in osteoarthritis. Scand. J. Rheumatol. Suppl., 81, 24-27.

Anderson, I. F. (1982). Intramuscular Arteparon in osteo-

\section{Diclofenac}

Although designed as a feasibility study of placebocontrolled trials in OA, no increase in the rate of radiographic progression was seen in patients treated with diclofenac slow-release $100 \mathrm{mg}$ (Dieppe et al ., 1990), compared with those on placebo. However only 51/89 patients completed 2 years therapy, with withdrawals mainly due to toxicity (5 placebo: 6 diclofenac) or lack of efficacy ( 3 diclofenac: 12 placebo).

\section{Hyaluronic acid}

Hyaluronic acid has been suggested to be a CPA but although it may produce symptomatic relief in doubleblind, placebo-controlled studies (Dixon et al., 1988; Grecomoro et al., 1987), no evidence of a chondroprotective effect in humans has been demonstrated.

\section{Conclusions}

The current therapy of OA depends on a careful approach to eliciting the source of symptoms. This relies on a careful clinical examination to localise tenderness to joint-line or periarticular sites, and to determine if a more widespread soft-tissue pain problem is present. Biomechanical factors, producing periarticular pain or malalignment may respond well to biomechanical treatments. In particular muscle strengthening exercises and weight reduction are often beneficial.

Local periarticular tender sites arising from bursitis or enthesopathy may respond to local corticosteroid injection. More widespread pain resulting in the fibromyalgia syndrome should be approached with regard to improving aerobic fitness and consideration of a trial of antidepressants.

Pain, the predominant symptom should initially be treated by simple analgesics and regular and full dose paracetamol may be sufficient. If there is marked synovitis, local therapy in the form of corticosteroid injections can also be effective and should be considered, though benefit may only be temporary.

NSAIDs should only be used after careful assessment of risk, and consideration of the alternatives. Regular critical reassessments of continued use should be made and repeat prescribing avoided. There is currently little rational basis for preferring particular NSAIDs, but topical administration is attractive.

Antidepressants may have a place in the treatment of chronic pain and CPAs may be important drugs for the future.

A.J. and M.D. would like to thank the Arthritis and Rheumatism Council for financial support. arthrosis of the knee - a double blind trial. Akt. Rheumatol., 7, 164-166.

Bagge, E., Bjelle, A., Eden, S. \& Svanborg, A. (1991). Osteoarthritis in the elderly: clinical and radiological findings in 79 and 85 year olds. Ann. Rheum. Dis., 50, 535-539. 
Blackshear, J. L., Napier, J. S., Davidman, M. \& Stillman, M. T. (1985). Renal complications of nonsteroidal antiinflammatory drugs: identification and monitoring of those at risk. Semin. Arthritis. Rheum., 14, 163-175.

Blake, D. R., Merry, P., Unsworth, J., Kidd, B. L., Outhwaite, J. M., Ballard, R., Morris, C. J., Gray, L. \& Lunec, J. (1989). Hypoxic-reperfusion injury in the inflamed human joint. Lancet, i, 289-293.

Bloom, B. S. (1988). Cost of treating arthritis and NSAIDrelated gastrointestinal side effects. Aliment. Pharmac. Ther., 2S, 131-139.

Bradley, J. D., Brandt, K. D., Katz, B. P., Kalasinski, L. A. \& Ryan, S. I. (1991). Comparison of an antiinflammatory dose of ibuprofen, an analgesic dose of ibuprofen, and acetaminophen in the treatment of patients with osteoarthritis of the knee. New Engl. J. Med., 325, 87-91.

Brooks, P. M., Dougan, M. A., Mugford, S. \& Meffin, E. (1982). Comparative effectiveness of 5 analgesics in patients with rheumatoid arthritis and osteoarthritis. J. Rheumatol., 9, 723-726.

Buckland-Wright, J. C., Macfarlane, D. G., Lynch, J. A. \& Clark, B. (1990). Quantitative microfocal radiographic assessment of progression in osteoarthritis of the hand. Arthritis Rheum., 33, 57-65.

Burkhardt, D. \& Ghosh, P. (1987). Laboratory evaluation of antiarthritic drugs as potential chondroprotective agents. Semin. Arthritis Rheum., 17 (Suppl. 1), 3-34.

Carson, J. L., Strom, B. L., Morse, L., West, S. L., Soper, K. A., Stolley, P. D. \& Jones, J. K. (1987). The relative gastrointestinal toxicity of the nonsteroidal anti-inflammatory drugs. Arch. intern. Med., 147, 1054-1059.

Caruso, I. \& Bianchi Porro, G. (1980). Gastroscopic evaluation of anti-inflammatory agents. Br. med. J., 1, 75-78.

Chamchan, U., Waikakul, S. \& Pukanchana-Mo-Rakote, C. (1989). Clinical efficacy of glycosaminoglycan polysulfate for the treatment of osteoarthritis of the knee joint: a double blind controlled study. J. med. Ass. Thai., 72, 123127.

Coke, H. (1967). Long term indomethacin treatment for coxarthrosis. Ann. Rheum. Dis., 26, 346-347.

Coles, L. S., Fries, J. F., Kraines, R. G. \& Roth, S. H. (1983). From experiment to experience: side effects of nonsteroidal anti-inflammatory drugs. Am. J. Med., 74, 820-828.

Committee on the Safety of Medicines (1986). Non-steroidal anti-inflammatory drugs and serious gastrointestinal adverse reactions - 1. Br. med. J., 292, 614 .

Cushnagan et al. (1990).

Dieppe, P. A., Sathapatayavongs, B., Jones, H. E., Bacon, P. A. \& Ring, E. F. J. (1980). Intra-articular steroids in osteoarthritis. Rheumatol. Rehabil., 19, 212-217.

Dieppe, P., Cushnaghan, J., Jasani, K. \& McCrae, F., Watt, I. (1990). A two-year placebo controlled trial of a nonsteroidal anti-inflammatory (NSAID) in knee osteoarthritis (OA). Br. J. Rheumatol., 29 (Suppl. 2), 129.

Dixon, A. StJ., Jacoby, R. K., Berry, H. \& Hamilton, E. B. D. (1988). Clinical trial of intra-articular injection of sodium hyaluronate in patients with osteoarthritis of the knee. Curr. med. Res. Opin., 11, 205-213.

Doherty, M. (1989). "Chondroprotection" by non-steroidal anti-inflammatory drugs. Ann. Rheum. Dis., 48, 619-621.

Doherty, M. \& Dieppe, P. A. (1981). Effect of intra-articular yttrium-90 (90Y) on chronic pyrophosphate arthropathy (CPA) of the knee. Ann. Rheum. Dis., 40, 626

Doherty, M., Watt, I. \& Kieppe, P. A. (1983). Influence of primary generalised osteoarthritis on the development of secondary osteoarthritis. Lancet, ii, 8-11.

Doherty, M., Holt, M., MacMillan, P., Watt, I. \& Dieppe, P. (1986). A reappraisal of "analgesic hip". Ann. Rheum. Dis., 45, 272-276.

Doogan, D. P. (1989). Topical non-steroidal anti-inflammatory drugs. Lancet, ii, 1270-1271.

Doyle, D. V., Dieppe, P. A., Scott, J. \& Huskisson, E. C. (1981). An articular index for the assessment of osteoarthritis. Ann. Rheum. Dis., 40, 75-78.

Felson, D. T., Anderson, J. J., Naimark, A., Kannel, W. \& Meenan, R. F. (1990). The prevalence of chondrocalcinosis in the elderly and its association with knee osteoarthritis: the Framingham study. J. Rheumatol., 16, 1241-1245.

Flanagan, J., Thomas, T. L., Casale, F. F. \& Desai, K. B. (1988). Intra-articular injection for pain relief in patients awaiting hip replacement. Ann. Roy. Coll. Surg. Eng., 70, 156-157.

Friedman, D. M. \& Moore, M. E. (1980). The efficacy of intraarticular steroids in osteoarthritis: a double-blind study. J. Rheumatol., 7, 850-856.

Gammer, W. \& Broback, L.-G. (1984). Clinical comparison of orgotein and methylprednisolone acetate in the treatment of osteoarthrosis of the knee joint. Scand. J. Rheumatol., 13, 108-112.

Gershon, S. (1986). Chronic pain: hypothesized mechanism and rationale for treatment. Neuropsychobiology, 15 (Suppl. 1), 22-27.

Gibson, T., Winter, P. J. \& Grahame, R. (1973). Radiotherapy in the treatment of osteoarthrosis of the knee. Rheumatol. Rehabil., 12, 42-46.

Golden, E. L. (1978). A double-blind comparison of orally ingested aspirin and a topically applied salicylate cream in the relief of rheumatic pain. Curr. Ther. Res., 24, 524-529.

Goldenberg, D. L. (1987). Fibromyalgia syndrome. J. Am. med. Ass., 257, 2782-2787.

Gramajo, R. J., Cutroneo, E. J., Fernandez, D. E., Gibson, J. L., Caceres Maldonado, J. C., Romero, F. L. \& Houssay, R. H. (1989). A single-blind, placebo-controlled study of glycosaminoglycan-peptide complex ("Rumalon") in patients with osteoarthritis of the hip or knee. Curr. med. Res. Opin., 11, 366-373.

Gray, R. G., Tenenbaum, J. \& Gottlieb, N. L. (1981). Local corticosteroid injection treatment in rheumatic disorders. Semin. Arthritis Rheum., 10, 231-254.

Grecomoro, G., Martorana, U. \& Di Marco, C. (1987). Intraarticular treatment with sodium hyaluronate in gonarthrosis: a controlled clinical trial versus placebo. Pharmatherapeutica, 5, 137-141.

Griffin, M. R., Piper, J. M., Daugherty, J. R., Snowden, M. \& Ray, W. A. (1991). Nonsteroidal anti-inflammatory drug use and increased risk for peptic ulcer disease in elderly persons. Ann. intern. Med., 114, 257-263.

Huskisson, E. C., Dieppe, P. A., Tucker, A. K. \& Cannell, L. B. (1979). Another look at osteoarthritis. Ann. Rheum. Dis., 38, 423-428.

Hutton, C. W. (1987). Generalised osteoarthritis: an evolutionary problem? Lancet, i, 1463-1465.

Jones, A. C., Berman, P. \& Doherty, M. (1992). Non-steroidal anti-inflammatory drug usage and requirement in elderly acute hospital admissions. Br. J. Rheumatol., (in press).

Kantor, T. G. (1989). Concepts in pain control. Semin. Arthritis Rheum., 18 (Suppl. 2), 94-99.

Keagy, R. D. \& Keim, H. A. (1967). Intra-articular steroid therapy: repeated use in patients with chronic arthritis, Am. J. med. Sci., 253, 45-51.

Kerzberg, E. M., Roldan, E. J. A., Castelli, G. \& Huberman, E. D. (1987). Combination of glycosaminoglycans and acetylsalicylic acid in knee osteoarthrosis. Scand. J. Rheumatol., 16, 377-380.

Kjaersgaard-Andersen, P., Nafei, A., Skov, O., Madsen, F., Andersen, H. M., Kroner, K., Hvass, I., Gjoderum, O., Pedersen, L. \& Braneberg, P. E. (1990). Codeine plus paracetamol versus paracetamol in longer-term treatment of chronic pain due to osteoarthritis of the hip. A randomised, double-blind, multi-centre study. Pain, 43, 309-318. 
Lawrence, J. S., Bremner, J. M. \& Bier, F. (1966). Osteoarthrosis: prevalence in the population and relationship between symptoms and x-ray changes. Ann. Rheum. Dis., 25 1-23.

Lewis, B. \& Lewis, D. (1985). Use of transcutaneous electrical nerve stimulation in the treatment of osteoarthritis: current status. Geriatric Medicine Today, 4, 101-108.

Mann, S. G. \& Young, J. H. (1989). Progression of osteoarthritis and drug treatment. Lancet, ii, 914.

Massardo, L., Watt, I., Cushnagan, J. \& Dieppe, P. (1989). Osteoarthritis of the knee joint: an eight year prospective study. Ann. Rheum. Dis., 48, 893-897.

Mayer, J. H. (1970). Carpometacarpal osteoarthritis of the thumb. Lancet, ii, 270.

Mazieres, B., Masquelier, A-M. \& Capron, M-H. (1991). A French controlled multicenter study of intraarticular orgotein versus intraarticular corticosteroids in the treatment of kenn osteoarthritis: a one-year followup. J. Rheumatol., 18 (Suppl. 27). 134-137.

MacAlindon, T. \& Dieppe, P. (1990). The medical management of osteoarthritis of the knee: an inflammatory issue? Br. J. Rheumatol., 29, 471-473.

McIlwain, H., Silverfield, J. C., Cheatum, D. E., Poiley, J., Taborn, J., Ignaczak, T. \& Multz, C. V. (1989). Intraarticular orgotein in osteoarthritis of the knee: a placebocontrolled efficacy, safety, and dosage comparison. Am. J. Med., 87, 295-300.

Mejersjo, C. (1987). Therapeutic and prognostic considerations in TMJ osteoarthrosis: a literature review and a longterm study in 11 subjects. Cranio., 5, 69-78.

Merritt, J. L. (1989). Soft tissue mechanisms of pain in osteoarthritis. Semin. Arthritis Rheum., 18 (Suppl. 2), 51-56.

Newman, N. M. \& Ling, R. S. M. (1985). Acetabular bone destruction related to non-steroidal anti-inflammatory drugs. Lancet, ii, 11-14.

Office of Population Censuses and Surveys (Social Survey Division). General Household Survey, London, H.M.S.O.

Parr, G., Darekar, B., Fletcher, A. \& Bulpitt, C. J. (1985). Joint pain and quality of life; results of a randomised trial. Br. J. Clin. Pharmacol., 27, 235-242.

Pastinen, O., Forsskahl, B. \& Marklund, M. (1988). Local glycosaminoglycan polysulphate injection therapy in osteoarthritis of the hand. Scand. J. Rheumatol., 17, 197-202.

Pattrick, M., Aldridge, S., Hamilton, E., Manhire, A. \& Doherty, M. (1989). A controlled study of hand function in nodal and erosive osteoarthritis. Ann. Rheum. Dis., 48, 978-982.

Paulus, H. E. (1985). FDA arthritis advisory committee meeting. Arthritis Rheum., 28, 450-451.

Pelletier, J. P. \& Martel-Pelletier, J. (1989). Protective effects of corticosteroids on cartilage lesions and osteophyte formation in the Pond-Nuki dog model of osteoarthritis. Arthritis Rheum., 32, 181-193.

Pond, M. J. \& Nuki, G. (1973). Experimentally-induced osteoarthritis in the dog. Ann. Rheum. Dis., 32, 387-388.

Pybus, P. K. (1987). Osteo-arthritis of the hip treated by intraneural injection a simplified technique for the relief of intractable osteoarthritis pain. Med. Hypotheses, 22, 357363.

Radin, E. L. \& Burr, D. B. (1984). Hypothesis: joints can heal. Semin. Arthritis Rheum., 13, 293-302.

Rashad, S., Revell, P., Hemingway, A., Low, F., Rainsford,
K. \& Walker, F. (1989). Effect of non-steroidal antiinflammatory drugs on the course of osteoarthritis. Lancet, ii, 519-522.

Reginister, J. Y., Gysen, P., Malaise, M. \& Franchimont, P. (1985). Influence of tiaprofenic acid on the synthesis and the physicochemical properties of articular proteoglycans in degenerative osteo-arthritis and rheumatoid arthritis. In New trends in rheumatology 3, ed. Nilsen, O. G., pp. 5358. Amsterdam: Excerpta Medica S. A.

Rejholec, V. (1987). Long-term studies of antiosteoarthritic drugs: an assessment. Semin. Arthritis Rheum., 17 (Suppl. 1), 35-53.

Ritter, M. A. \& Gioe, T. J. The effect of indomethacin on para-articular ectopic ossification following total hip arthroplasty. Clin. Othop., 167, 113-117.

Ronningen, H. \& Langeland, N. (1979). Indomethacin treatment in osteoarthritis of the hip joint. Acta Orthop. Scand., 50, 169-174.

Shamzad, M., Perkal, M., Golden, E. L. \& Marlin, R. L. (1986). Two double-blind comparisons of a topically applied salicylate cream and orally ingested aspirin in the relief of chronic musculoskeletal pain. Curr. Ther. Res., 39, 470479.

Siegmeth, W. \& Radi, I. (1983). Comparison of glycosaminoglycan polysulfate (Arteparon) and saline solution in osteoarthritis of large joints. Z. Rheumatol., 42, 223-228.

Somerville, K., Faulkner, G. \& Langman, M. (1986). Nonsteroidal anti-inflammatory drugs and bleeding peptic ulcer. Lancet, i, 462-464.

Stamp, J., Rhind, V. \& Haslock, I. (1989). A comparison of nefopam and flurbiprofen in the treatment of osteoarthrosis. Br. J. clin. Pract., 43, 24-26.

Steele, K., Mills, K. A., Gilliland, A. E. W., Irwin, W. G. \& Taggart, A. (1987). Repeat prescribing of non-steroidal anti-inflammatory drugs excluding aspirin: how careful are we? Br. med. J., 295, 962-964.

Summers, M. N., Haley, W. E., Reveille, J. D. \& Alarcon, G. S. (1988). Radiographic assessment and psychologic variables as predictors of pain and functional impairment in osteoarthritis of the knee or hip. Arthritis Rheum., 31, 204-209.

Thonar, E. J.-M. A., Lenz, M. E., Klintworth, G. K., Caterson, B., Pachman, L. M., Glickman, P., Katz, R., Huff, J. \& Kuettner, K. E. (1985). Quantification of keratan sulfate in blood as a marker of cartilage catabolism. Arthritis Rheum., 28, 1367-1376.

Troyer, H. (1982). Experimental models of osteoarthritis: a review. Semin. Arthritis Rheum., 11, 362-374.

Valtonen, E. J. (1981). Clinical comparison of triamcinolonehexacetonide and betamethasone in the treatment of osteoarthrosis of the knee joint. Scand. J. Rheumatol. Suppl., 41, 1-7.

Vignon, E., Mathieu, P., Couprie, N., Cloppet, H., Herbage, D., Louisot, P., Richard, M. (1990). Effects of tiaprofenic acid on interleukin 1, phospholipase A2, neutral protease, and collagenase activity in rheumatoid synovial fluid. Semin. Arthritis Rheum., 18 (Suppl. 1), 11-15.

Wall, P. A. (1984). Mechanisms of acute and chronic pain. Adv. Pain Res. Ther., 6, 95-104.

(Received 5 September 1991, accepted 5 November 1991) 